\title{
Theoretical analysis of information cascade in investment market
}

\author{
ZHOU Xiangdong \\ School of Economics, Jiangsu University of Technology, Changzhou 213001, China
}

XIONG Yan

School of Foreign Languages, Jiangsu University of Technology, Changzhou 213001, China

LIU Fan

School of Economics, Jiangsu University of Technology, Changzhou 213001, China

\begin{abstract}
In recent decades continuous financial crisis has become an important research topic in economics. The formation of the financial crisis has been investigated in terms of price bubble, informational cascade, herd behaviour, irrational speculation. This paper employs BHW model to analyze the informational cascade and herd behaviour in the financial crisis and to summarize the formation of the current financial crisis.
\end{abstract}

KEYWORD: financial crisis; information cascade; herd behaviour; BHW model

Since the early 1990's, the world's financial markets have been constantly suffering from the regional financial crisis, bringing impacts of various degrees on all the countries. The global financial crisis in 2007 and 2008 trigged by the US subprime crisis has directly led to the current global recession. Current analysis of the causes of the financial crisis has deviated from the traditional theory of fluctuations of prices in foreign exchange market and asset market, focusing on links among price bubble, information cascade, herd behavior and irrational speculation. This paper employs the Sushil Bikhchandani, David Hirshleifer, and Ivo Welch (1992) model (BHW model) to analyze informational cascade and herd behavior, thus providing profound theoretical understanding of the causes of the financial crisis.

\section{INFORMATION CASCADE AND HERD BEHAVIOR}

As a special phenomenon in the investment market, herd behavior means that investors abandon what they believe to be their own available information and follow the behavior of other investors instead, although their own available information indicates that they should have an entirely different investment behavior. Such investors observe the other investor's behaviors and make the same decision as the others, disregarding their own private information. This phenomenon is called informational cascade. If all the investors make the same investment decision, the possible result might be that all the investors, or most of them invest in or sell an investment property. This is the so-called herd behavior. This investment behavior will lead to substantial price fluctuations of the invested property. As pervasion is one of its notable features of herd behavior, when it occurs in the financial market, confusion in financial markets will be likely to happen, triggering a financial crisis.

BHW model is also known as the basic model of the informational cascade, which involves the special form and the general form. In the special form some of the parameters are fixed, while in the general form some of the parameters are changeable. With the reserarch aim to find out how the information cascade emerge in the financial market, the special form is more applicabe than the general form.

\section{ASSUMPTIONS OF THE BHW MODEL}

The following are the main assumptions in BHW model for analyzing the form of information cascade:

- All investors will decide whether to invest (referred to as A) or not to invest (the R) in an asset, Such assets can real estate or stocks. The ppurpose for investment is to achieve the profit maximization.

- Each investor can observe the decisions of all those ahead of him, and make his own decision. There is a sequence of investment decisions by all the investor and the ordering is exogenous and is known to all. There is no other form of information exchange among the investors. 
- Investors obtain information by observing the investment decision ahead of them (public information). This information is known as public information.

- Investors make their decisions in an uncertain situation, which means the investment profit (V) is uncertain when investors decide to invest. Investment profit depends on the actual value of investment property, which is not known to investors when they make decisions.

- The real value of the investment properties are divided into two environmental states: good situation (G) and bad situation (B). The expected investment profit $\mathrm{V}$ appears only in these two forms. Return on investment by the real value of investment properties as a good situation $(\mathrm{G})$ is formulated as $\mathrm{V}$ $=1$. When the investment property is in bad situation $\mathrm{B}$, the investment return is formulated as $\mathrm{V}=0$.

- If investors choose to invest, it will result in some costs $\mathrm{C}$. In the model $\mathrm{C}=0.5$, the costs are the same for all the investor. If investors choose not to invest, there will be no such costs.

- There is a prior probability of each situation (good situation and bad situation). The probability of the selection of investment in good situation and the probability of non-investment in bad situationtion is equal to 0.5 , which is formulated as $P_{r}(V=1)=P_{r}(V=0)=0.5$.

- Each investor has his private signal (private information) about the actual value of investment, which will not be observed by other investors. If investors make investment decisions according to their own private signal, then this signal will be feedback into his investment decisions. In good situation investors may invest, while in bad situation they may not invest. The amount of private signal has the characteristics of duality. Each investor's private signal $\mathrm{X}$ contains two values: $\mathrm{H}$ for the highprecision (the possibility $p$ is greater than 0.5 ), $\mathrm{L}$ for the low-precision (the probability is $1-p<0.5$ ). Private signal can be transmitted through the investment the behavior of investors. The formulas are as the follows:

$$
\begin{gathered}
r F P \neq H V \neq=P X(=L V \vDash \theta \sigma \\
-1 \neq P X \neq H V \neq=\Rightarrow P X(=L V \vDash \triangleleft \sigma
\end{gathered}
$$

Formula (1) indicates that if investment profit is 1 (or 0 ), the possibility, which the investor receives the high-precision signal $(\mathrm{H})$ or low-precision signal (L), is more than 0.5. Formula (2) implies that if investment profit is 0 (or 1), the possibility, which the investor receives the high-precision signal $(\mathrm{H})$ or low-precision signal (L), is less than 0.5. Here $p$ also reflects the precision of the information and this precision for all the investors remains the same. Although transmittable, the information cannot be $100 \%$ transmitted. Therefore, the characteristics of information transmission meets with the conditions of $0.5<p<1$, which means that is very difficult for investors to rely only on their own private information to make accurate decision.

\section{THE FORMATION OF INFORMATIONAL CASCADE AND HERD BEHAVIOR}

The limitations of information's transmission require investors to make a decision, based not only on private signal but also on the decisions of other investors. By using Bayesian theorem, investors can make prior probability of real value of investment properties to posterior probability, and use the posterior probability to calculate the expected return on investment in oder to make investment decision. Bayesian theorem is the standard method in the economic analysis, it is the rule of the relationship between the prior probability and the posterior probability of two randomly events. Assume that $\gamma$ is the posterior probability, if the return of investment is $\mathrm{V}=1$, then the expected investment income $\mathrm{E}(\mathrm{V})$ is composed of different benefits and randomiy possibilities, which is formulated as:

$$
E(V)=\gamma \times 1+(1-\gamma) \times 0=\gamma
$$

Expected return minus the investment cost $\mathrm{C}$ is the expected net profit of the investment $(\mathrm{E}(\mathrm{V})-\mathrm{C})$. Investment behavior can be divided into the following three types. 1) When the expected net profit of the investment is greater than 0 , investor will choose to invest. 2) When the expected net profit of the investment is equal to 0 , investor can choose to invest, or not to invest. 3) When the expected net profit of the investment is less than 0 , then investor will choose not to invest. In BHW model the most crucial step in the analysis of form of an informational cascade and herd behavior is find out how to realize the prior probability to the posterior probability. The following analysis of the first three investors in the BHW model can determine whether the informational cascade, namely, herd behavior, has generated.

\section{THE ANALYSIS OF THE FIRST INVESTOR'S BEHAVIOR}

The first investor made his investment decision primarily based on his private signal. The private signal has two forms: a high precision of signal $(\mathrm{H})$ and a low precision of signal (L). If the investor's private signal is a high precision signal, its investment decision can be divided into two analysis 
steps: First, Bayesian theorem is used to make the prior probability with the expected investment return for $1\left(P_{r}(V=1)=0.5\right)$ to the posterior probability of the expected investment return for $1\left(P_{r}(V=1 / X=H)\right)$ under the condition of high precision signal, which is formulated as the following:

$$
\begin{aligned}
P_{r}(V=1 / X=H)=\frac{P_{r}(X=H / V=1) * P_{r}(V=1)}{P_{r}(X=H / V=1) * P_{r}(V=1)+P_{r}(X=H / V=0) * P_{r}(V=0)} \\
=\frac{p * 0.5}{p * 0.5+(1-p) * 0.5}=\frac{p * 0.5}{0.5}=p
\end{aligned}
$$

Formula

shows

that $E(V)=\gamma=P_{r}(V=1 / X=H)=p$, and $p>0.5$ is known, so the posterior probability is greater than prior probability $\left(p>P_{r}(V=1)=0.5\right)$.

Secondly, posterior probability is used to calculate the expected net investment profit: $\mathrm{E}(\mathrm{V})$ $\mathrm{C}=\mathrm{E}(\mathrm{V})-0.5>0$. When the first investor has high precision of private signal and the expected return is 1 , he will choose to invest. On the contrary, if the investor has a low precision of private signal, and the expected return is the same as 1 , and its expected net investment return is negative (calculated the same process as above), he will not choose to invest.

As the first investor makes his investment decision according to his own information only, the investment decision can relay his private signal. If he invests, it indicates that he has a high precision of private signal. If he does not invest, however, it indicates that he has a low precision of private signal. This means that the act of the first investor can transmit his private signal to the second investor.

\section{THE ANALYSIS OF THE SECOND INVESTOR'S BEHAVIOR}

In addition to his own private signal, the second investor can observe the behavior of the first investor and obtain the information (public information). His investment behavior can be analyzed in following situations:

The first investor decides to invest (A) when he has high precision of private signal $(\mathrm{H})$. If the second investor also has a high precision of private signal $(\mathrm{H})$, what will he choose to invest? Similarly, by using the Bayesian theorem, we can calculate the posterior probability of the expected investment returns to be $1, \gamma=W(V=1 / X=H, H)$. At this time, the two H's in the formula represent that both the first and the second investors have the same high precision of private signal as expressed in the following formula:

$$
\begin{aligned}
P_{r}(V & =1 / X=H, H)=\frac{P_{r}(X=H, H / V=1) * P_{r}(V=1)}{P_{r}(X=H, H / V=1) * P_{r}(V=1)+P_{r}(X=H, H / V=0) * P_{r}(V=0)} \\
& =\frac{p * p * 0.5}{p * p * 0.5+(1-p)(-1 p * 05}=\frac{p^{2} * \text { (5 }}{p^{2}-p+C 5}
\end{aligned}
$$

As $p$ is greater than $0.5, P_{r}(V=1 / X=H, H)$ will also be greater than 0.5 , According to the posterior probability, we can calculate the expected investment return to be greater than 0.5 as well. The expected net profit for investment is $\mathrm{E}(\mathrm{V})-\mathrm{C}=\mathrm{E}(\mathrm{V})$ $-0.5>0$. In this case, the second investor will undoubtedly choose to invest.

If the first investor has a high precision of private signal $(\mathrm{H})$ and decides to invest $(\mathrm{A})$, what will the second investor choose to invest, if he has a low precision of private signal (L)? Again, we can use the Bayesian theorem to calculate the posterior probability of the expected investment returns for 1 , while he has the low precision of private signal:

$$
\begin{aligned}
P_{r}(V & =1 / X=H, L)=\frac{P_{r}(X=H, L / V=1) * P_{r}(V=1)}{P_{r}(X=H, L / V=1) * P_{r}(V=1)+P_{r}(X=H, L / V=0) * P_{r}(V=0)} \\
& =\frac{p *(1-p) * 0.5}{p *(1-p) * 0.5+(1-p) * p * 0.5}=\frac{p *(1-p) * 0.5}{p(1-p)}=0.5
\end{aligned}
$$

The posterior probability is equal to the prior probability probability, because the decision of the first investor (A) adequately reflects his private signal $(\mathrm{H})$, while the second investor has a low precision of his private signal (L). Expected investment income $E(V)=P_{r}(V=1 / X=H, L) * 1$ $=0.5$. The net income profit for investment is $\mathrm{E}(\mathrm{V})-$ $\mathrm{C}=\mathrm{E}(\mathrm{V})-0.5=0$. In this case, the possibility of the choice for investment or non-investment for the second investor with low precision of private signal (L) is $50 \%$.

The first investor has low precision of private signal (L), so he chooses not to invest (R). Then whatwill the second investor decide to invest? Similarly, if the second investor also has a low precision of private signal L, then he will choose not to invest. If the second investor has a high precision of private signal $\mathrm{H}$, then the possibility of investment or non-investment is $50 \%$ as deduced above.

The analysis in these three situations reflects that the second investor's decision can only transmit part of his private information to the third investor. The reason is that if the second investor's decision is inconsistent with the decision of the first investor, the second investor's decision can only be reference to his own private signal. Likewise, if the two 
investors have the same precision of personal signal, they will make the same decision. The second investor makes decision according to his own private signal along with the decision of the first investor (public information). In this case, there is no in the first two investors' decision-making. Informational cascade emerges only in the third investor's behaviour.

\section{THE ANALYSIS OF THE THIRD INVESTOR'S BEHAVIOR}

The third investor's behavior can also be analyzed from the following aspects:

When both the first and the second investors have chosen to invest (AA), the third investor will choose to invest as the other two investors have done (A), despite of his the high precision or low precision of private signal. Here we can analyze from two aspects. Firstly, when the three investors have the high precision of private signal $(\mathrm{H})$, they will all undoubtedly choose to invest (A). Secondly, when the third investor has the low precision of private signal (L), why would he also choose to invest? We can find the answer to this question via the calculation of the posterior probability. The third investor can make his judgment according to the other two investment sequences (AA). If the first investor chooses to invest (A), it shows that his personal signal is $100 \%$ the high precise signal. However, the second investor's private information cannot be $100 \%$ accurate in terms of a high precise or a low precise signal. The probability is $50 \%$.

The analysis of the second investor indicates that with a high precision of private signal, he will choose to invest. For the third investor, however, the probability is $P_{r}(H H / A A)$. This is the possibility for the first and the second investors' investment when they both have high precision of private signal. When the second investor has a low precision of private signal according to the decision of the first investor, the probability of his decision to invest will be $50 \%$, which is $P_{r}(H L / A A)$. The possibility of a high precision of private signal and a low precision of private signal when both of them choose to invest can be calculated via the following formula:

$$
P_{r}(H H / A A)=\frac{\left(1-2 p+2 p^{2}\right)}{1-p+p^{2}}>P_{r}(H L \mid A A)=\frac{p(1-p)}{1-p+p^{2}}
$$

Obviously, when the second investor makes choice to invest, the probability of his private signal, which is a high precise signal, is greater than the probability of his private signal, which is a low precise signal. After the accounting of net investment profit, the third investor will choose the same investment decision as the other two investors have done. The third investor ignores his own private signal and makes decision based on the decisions by the other two investors. At this time, his own private signal is usually neglected. When all the investors have the same decision for investment, it is called "up cascade" or "investment cascade". This phenomenon appears in the decision-making by the third investor, who follows the decisions by the other two investors, ignoring his private signal.

When both the first and the second investors have chosen not to invest (RR), the third investor will probably ignore his private signal and choose not to invest either. This chain phenomenon is called "down cascade" or "non-investment cascade".

In the above analysis, we can see that all the three investors have made the same decision. For the other investors who follow, the decision of the third investor can not transmit the right private signal, because it is not based on his private signal, but rather it is simply an imitation of the behavior of the other two investors ahead. For the fourth investor, the third investor's decision no longer reflects the private signal of the third investor.

The fourth investor has the same problem as the third investor does. He makes the same decision as the third investor through the same reasoning. His decision is a part of the informational cascade, which means that he imitates the behavior of the other investors. The same principle applies to the subsequent interpretation of decisions of the other investors who follow. The end of information feedback marks the beginning of the informational cascade. he informational cascade of "investment cascade" or "non-investment cascade" depends on the order of private information. In the case of two H's and two L's, if the sequence is HHLL, "investment cascade", appears. If the sequence is a LLHH, on the other hand, "non-investment cascade" appears.

When both the first and the second investors make different investment decisions, it reflects the quality of their private signal. If the first investor chooses to invest while the second investor chooses not to invest, it reflects that the first investor has a high precision of private signal, while the second investor has a low precision of private signal.

In his decision-making, if the third investor depends on his own private signal instead of that of the others. Informational cascade (herd behavior) will not occur. From the above analysis, the information cascade normally only occurs from the third investor whose decision-making is significantly affected by the others' decisions and quality of the private signal.

\section{CONCLUSIONS}

Through analysis of the BHW model we can see that when investors ignore their own signals and follow 
the decisions of the other investors, the informational cascade and herd behavior occur. Although the analysis of BHW model would be limited by such conditions as is fixed asset price in the model, the only two identified values ( 1 or 0$)$ in the expected return of investment, it is still applicable in explaining the formation of the informational cascade and herd behavior. When the US subprime crisis triggered the world financial crisis, such non-rational behavior in finance market has become a topic for discussion. At the beginning of this century the Federal Reserve low interest rate policy caused the housing price bubble (investment cascade in house market). When some banks, insurance companies, hedge funds ignored the risk, developed and invested special in collateralized debt obligations (CDOs) in pursuit of high profits, they caused great global capital flow, bringing "investment cascade". When the Federal Reserve curbed the overheated real estate economy and raised the benchmark interest rate, the real estate bubble burst, causing "sell cascade", People started to sell real estate, collateralized debt obligations, so the prices of the real estate and collateralized debt obligations declined quickly. When banks, insurance companies, hedge funds had liquidity problems or became bankrupt, the international financial markets lacked a sense of trust. The ultimate result was that enterprises had not bank loans, forming a "non- investment cascade". The global financial crisis has evolved into a global economic recession.

\section{REFERENCES}

[1] Hott, C. Finanzkrisen: Eine portfoliotheoretische Betrachtung von Herdenverhalten und Ansteckungseffekten als Ursachen von Finanzkrisen, Dresden, 2002: 1-177.

[2] Bikhchandani, S./Hirshleifer, D./Welch, I. A Theory of Fads, Fashion, Custom, and Cultural Change as Informational Cascades. Journal of Political Economy, 1992, 100(5): 992 - 1026.

[3] Chamley, C. Rational Herds: Economic Models of Social Learning. Cambridge. 2004: 19-23.

[4] Bikhchandani, S./Hirshleifer, D./Welch, I. Learning from the Behavior of Others: Conformity, Fads, and Informational Cascades. Journal of Economic Perspectives, 1998, 12(3): 151 - 170.

[5] Bikhchandani, S./Sharma, S. Herd Behavior in Financial Markets. IMF Staff Papers, 2001, 47(3): 279-310.

[6] Hirshleifer, D./Welch, I. (2002): An Economic Approach to the Psychology of Change: Amnesia, Inertia, and Impulsiveness. Journal of Economics \& Management Strategy, 2002, (11): 379 - 421.

[7] Anderson, L. Payoff Effects in Information Cascade Experiments. Economic Inquiry, 2001, 39(4): 609 - 615.

[8] Hirshleifer, D./Teoh, S. Herd Behavior and Cascading in Capital Markets: A Review and Synthesis. European Financial Management, 2003, 9(1): 25 - 66. 